\title{
The dynamics of a newly floating exchange rate: the Turkish case
}

\section{Oya Pınar Ardıç \& Faruk Selçuk}

To cite this article: Oya Pınar Ardıç \& Faruk Selçuk (2006) The dynamics of a newly floating exchange rate: the Turkish case, Applied Economics, 38:8, 931-941, DOI: 10.1080/00036840600649732

To link to this article: http://dx.doi.org/10.1080/00036840600649732

册 Published online: 02 Feb 2007.

Submit your article to this journal $\pi$

Џll Article views: 89

Q View related articles $₫$

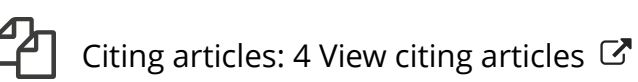




\title{
The dynamics of a newly floating exchange rate: the Turkish case
}

\author{
Oya Pınar Ardıç ${ }^{\mathrm{a}, *}$ and Faruk Selçuk ${ }^{\mathrm{b}}$ \\ ${ }^{a}$ Bogazici University, Department of Economics, Bebek 34342, Istanbul, \\ Turkey \\ ${ }^{\mathrm{b}}$ Department of Economics, Bilkent University, Bilkent 06800, Ankara, \\ Turkey
}

In recent years, many emerging market economies have switched or are in the process of switching to a floating exchange rate regime. Most of these economies have a history of high inflation and a high level of foreign currency denominated debt. Therefore, the stability of the exchange rate and the dynamics of its volatility are more crucial than before. This paper analyses the dynamics of exchange rate in Turkey in the aftermath of recent float in February 2001. The Turkish experience is a particularly important one, and provides valuable lessons for other countries as the Central Bank is trying to simultaneously contain the volatility of exchange rate and pursue an implicit inflation targeting policy. The reported findings indicate that the Central Bank policies, accompanied with favourable external factors, were effective in taming the volatility of the exchange rate in a relatively short period of time. However, there is a significant real appreciation of the currency during the same period. Given the high level of public debt and real interest rates, the current state of the economy is very susceptible to any adverse shocks.

\section{Introduction}

Since the last decade of the 20th century, the emerging market economies have been adversely affected by the crises in the international capital markets. The Asian crisis of 1997-1998 and the following crises in Brazil, Russia, Turkey, and Argentina coupled with the increased integration of capital markets around the world have led to the question of the appropriate exchange rate regime for an emerging economy under free capital mobility. The policy choices, since then, have been 'bipolar' in the sense that the two extreme regimes, hard pegs and free floats, have been favoured and the intermediate regimes have lost their attractiveness. Although the intermediate regimes seem to be disappearing, Fischer (2001), Calvo and Reinhart (2002), Reinhart (2000) among others, put forth the existence of 'fear of floating', i.e., a country will not remain indifferent to wide fluctuations in its exchange rate even when it has openly committed to a float. Taylor and Sarno (2001) consider whether the foreign exchange intervention is effective, and if so the mechanisms through which it works. Their conclusion is that intervention can be effective even in developed markets. However, if there is a coordination failure in intervention, it may be hard for the officials to influence the exchange rates. $^{1}$

\footnotetext{
*Corresponding author. E-mail: pinar.ardic@boun.edu.tr

${ }^{1}$ See Fischer (2001) for a review of exchange rate regimes around the world, and the 'bipolar' view. Tavlas (2003) provides a review of exchange rate systems, emphasizing the choice of an exchange rate regime for an emerging economy. Taylor and Sarno (2002) covers the recent literature on exchange rate economics including diverse topics such as foreign exchange market efficiency, purchasing power parity hypothesis, exchange rate determination, monetary integration, foreign exchange market intervention, speculative attacks, currency crises and market microstructure.
} 
In this context, a literature exploring the exchange rate regime options for emerging market economies has flourished. Obstfeld and Rogoff (1995), Mussa et al. (2000) are two examples of the advocates against pegs, while Reinhart (2000), and Calvo and Reinhart (2001, 2002) argue for the peg for emerging markets. ${ }^{2}$ In addition, Cespedes et al. (2000), Allen et al. (2002), Cavallo et al. (2002) and Calvo et al. (2003) are among the studies that stress the importance of exchange rate volatility under a high degree of liability dollarization, a condition which most emerging economies suffer. A high degree of liability dollarization makes the economy more vulnerable to external shocks by magnifying the effects of the latter, and may trigger a crisis.

As many emerging market economies have switched or are in the process of switching to a floating exchange rate, the question of the effects of exchange rate volatility on other macroeconomic variables arises. Most emerging economies have a history of high inflation and a high degree of foreign currency denominated debt. Therefore, the stability of the exchange rate and its volatility is crucial. This paper analyses the dynamics of the exchange rate and its volatility in Turkey in the aftermath the recent float in February 2001. The Turkish experience is a particularly important one, and provides valuable lessons for other countries as the Central Bank is simultaneously trying to contain the volatility of exchange rate and pursue an implicit inflation targeting policy. The present findings indicate that the Central Bank policies, accompanied with favourable external factors, were effective in taming the volatility of the exchange rate in a relatively short period of time. Estimated model parameters show that there is a significant fall in both the unconditional mean of the daily squared shocks to exchange rate return and conditional volatility throughout the floating exchange rate period. Furthermore, the distribution of exchange rate return seems to be Normal in recent months.

The Turkish economy has been characterized by high levels of inflation and several stabilization attempts since the early 1980s. At the end of 1999, the Turkish government signed a stand-by agreement with the IMF and started to implement another inflation stabilization programme, based on a fixed exchange rate. The programme was unsuccessful as it started with an already overvalued currency and the overvaluation continued during the programme. In addition to the real appreciation of the currency, low real interest rates led to increased imports and a high current account deficit. Excessive risk-taking behaviour of the banking sector and the moral hazard created by the fixed exchange rate programme are among other factors for the failure (Dornbusch, 2001, Eichengreen, 2001; Gençay and Selçuk, 2005). The short-lived crisis during the programme in November 2000, caused by an extremely risky position of a private bank, was overcome temporarily. However, adverse political developments and the loss of confidence in the authorities triggered another crisis in February 2001. Eventually, the Central Bank had to abandon the fixed parity and announced that the country moved into a floating exchange rate regime. In several announcements, authorities made it clear that the Central Bank would stick to this policy. ${ }^{3}$

Following the crisis, the challenge for the Central Bank was to re-establish confidence and contain volatility in financial markets while implicitly targeting inflation under a floating exchange rate system. Among the factors turning this into a challenge are a history of high inflation, no experience of a free float and a high level of liability dollarization and currency substitution in the economy. In a different context, Selçuk and Ardiç (2005) show that the Central Bank was indeed successful in containing exchange rate volatility. However the economy is not free from significant risks. Particularly, the current record level of real appreciation of the Turkish lira, along with a possible slow down in productivity may result in a large current account deficit. Selçuk and Ardıç (2005) report that this high level of appreciation is not as a result of the initial overshooting in February 2001. During the float, i.e., since March 2001, the overall real appreciation as measured by the two real effective exchange rate indices published by the Central Bank is in between 28 and $42 \%$ as compared to 1995 , which was a 'normal' year in terms of the real exchange rate level. The current high level of the total public debt with relatively high real interest rates increase the fragility of the system: the possibility of a large current account

\footnotetext{
${ }^{2}$ Earlier literature on the choice of optimum exchange rate regime includes Mundell (1961), McKinnon (1963), and Kenen (1969).

${ }^{3}$ Gençay and Selçuk (2005) provide an anecdotal story of the February 2001 crisis in Turkey. For a detailed account of the recent developments in the Turkish economy from different perspectives, see Ertuğrul and Selçuk (2002), Metin-Özcan et al. (2001), Öniş and Rubin (2003) and references therein. A series of articles in Kibritçioğlu et al. (2002) provides a detailed analysis of inflation dynamics and disinflation efforts in Turkey. For earlier studies, see Metin (1995) and Lim and Papi (1997). More recent studies are Celasun et al. (2003) and Domaç and Bahmani-Oskooee (2002).
} 


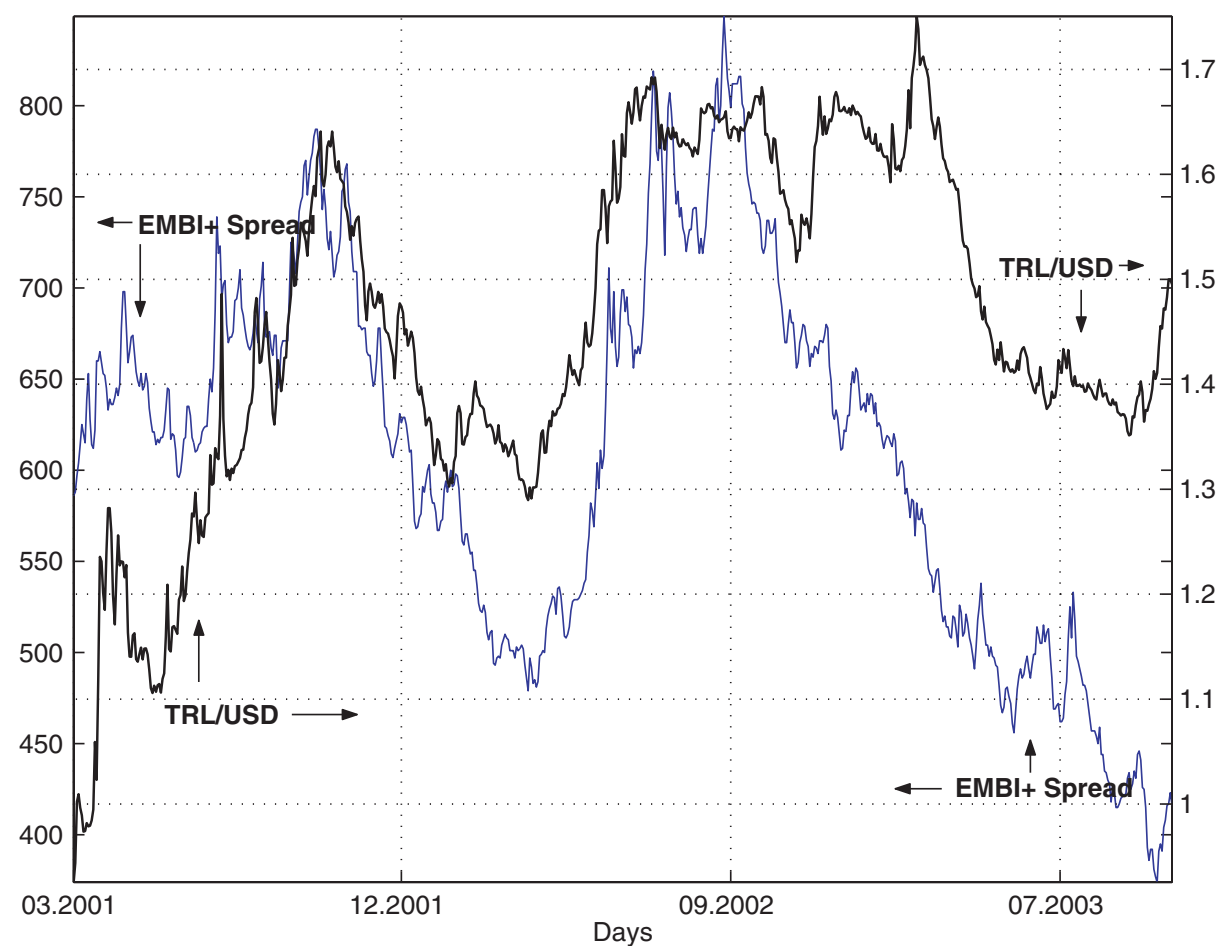

Fig. 1. EMBI+ daily spread (basis point, left axis) versus TRL/USD daily exchange rate (TRL million, right axis). Sample period: 13 March 2001 - 30 October 2003 (667 business days). Data sources: J.P. Morgan Chase and the Central Bank of Turkey

deficit and a upward correction in nominal exchange rates lead to an increased risk premium of the country, further worsening the fiscal position of the government.

If the Central Bank is pursuing a free float as stated, what might be the reason behind this high level of appreciation? The record level of the real appreciation may be explained in part by the productivity increase in tradeable goods sector (the so-called 'Balassa-Samuelson effect'). Labour productivity in private manufacturing industry increased $20 \%$ between 2001 and 2003 (second quarter) and there was a fall in hourly nominal wages (in USD terms) during the same period, leading to a fall in unit wages in USD terms. In addition, favourable external factors that may have led to the real appreciation of the Turkish lira need to be considered as well. As the findings of this paper indicate, the spread between emerging market bonds and US treasury bills is a significant variable in explaining the nominal exchange rate dynamics in Turkey (see Fig. 1). Particularly, a decrease in this spread is usually followed by a nominal appreciation of the Turkish lira and vice versa. Currently, the spread is at its historical lows and an adverse movement in this front may trigger an increase in the nominal exchange rate and its volatility in Turkey.

The paper is structured as follows. The next section analyses the interaction among Central Bank's policies, the exchange rate return and its volatility, and the external effects employing a VAR model. The volatility dynamics of the exchange rate return at different periods of float are studied in an ARMA-GARCH framework in the third section. Section IV concludes.

\section{Central Bank Policies and Exchange Rate}

In this part, a six variable VAR system is estimated using daily data in order to investigate the interaction among the Emerging Markets Bond Index Plus $(\mathrm{EMBI}+)$ spread, $^{4}$ the exchange rate return and

\footnotetext{
${ }^{4}$ The EMBI+ of J.P. Morgan Chase shows the dynamics of total returns for the external debt instruments of the emerging market economies, including external currency-denominated Brady bonds, loans and Eurobonds, US dollar domestic instruments, thus serving as a benchmark for emerging country external debt. The EMBI + spread is the spread between emerging market bonds and US treasury bills.
} 
Table 1. Granger causality probabilities. Sample period: 13 March 2001 - 30 October 2003 (667 business days). The rows show equations. The reported probabilities are probabilities that the column variable does not Granger cause the row variable

\begin{tabular}{lllllll}
\hline & EMBI + & Return & Volatility & Int. rate & But auction & Sell auction \\
\hline EMBI+ & 0.00 & 0.39 & 0.78 & 0.62 & 0.78 & 0.00 \\
Return & 0.00 & 0.00 & 0.13 & 0.65 & 0.30 & 0.00 \\
Volatility & 0.57 & 0.00 & 0.00 & 0.00 & 0.45 & 0.00 \\
Interest rate & 0.57 & 0.14 & 0.00 & 0.84 & 0.09 & 0.42 \\
Buying auction & 0.97 & 0.91 & 0.96 & 0.27 & 0.00 & 1.00 \\
Selling auction & 0.58 & 0.03 & 0.11 & 0.17 & 0.95 & 0.00 \\
\hline
\end{tabular}

its volatility, and the Central Bank policies. The variables in the system are the EMBI+ spread, the TRL/ USD exchange rate return (log difference, per cent), the absolute value of the exchange rate return as a measure of volatility (per cent), the change in the Central Bank overnight interest rates (simple annual, per cent), the daily total amount bought by the Central Bank in USD buying auctions and the amount sold by the Central Bank in USD selling auctions (million USD). The sample period is 13 March 2001 - 30 October 2003. Officially, the floating period started on 22 February 2001. The first eight business days after the float have been excluded to avoid any start-off effects in variables.

There are arguments that, since May 2003, the Central Bank policies are targeting both the level and direction of the exchange rate in addition to containing its volatility, and the recent buying auctions and direct buying interventions of the Central Bank might be in response to the strong (nominal and real) appreciation of the Turkish lira. That is, there might be a regime change in terms of the policy conduct. However, as documented elsewhere (Selçuk and Ardiç, 2005) no evidence is found for a policy change during the mentioned period.

The VAR model for the sample period is estimated by using a constant term and seven lags as indicated by Sims' Likelihood Ratio (LR) test (Sims, 1980). ${ }^{5}$ Adjusted $R$-squares of the estimated equations lie between 0.03 (change in the interest rate equation) and 0.78 (buying auctions equation). Table 1 reports the probabilities of the $F$-test that the column variable does not have any power in explaining the row variable. According to the results, the Granger causality tests indicate that the EMBI+ spread causes exchange rate return at $1 \%$ level of significance. That is, the lagged values of EMBI+ spread are statistically significant at $1 \%$ significance level in exchange rate return equation while the lagged values of exchange rate return have no explanatory power in the EMBI+ spread equation. This finding confirms the casual observation presented in Fig. 1 and indicates that the exchange rate dynamics in Turkey are sensitive to the international interest rate differential between developed and developing economies. Among other variables, exchange rate return causes volatility, and selling auction of the Central Bank causes the EMBI+ spread at $1 \%$. Notice that causality tests are conducted to determine which variable in an estimated system comes first. Therefore, this finding should be interpreted with caution. According to the result of the causality tests, feedback is observed among exchange rate return and selling auctions, and changes in the interest rate and exchange rate volatility at $5 \%$ and $1 \%$ significance levels respectively.

Figure 2 plots the response of exchange rate return to shocks to different variables in the system, along with $95 \%$ bootstrap confidence intervals. The response of exchange rate return to a positive shock in the EMBI+ spread (11 percentage points increase) is positive and significant after 1 day ( $0.2 \%$ increase). A significant negative response is observed after six days but the magnitude of this negative response is smaller than the positive one $(0.11 \%$ decrease $)$. Overall, it can be concluded that the exchange rate depreciates as a response to an unexpected increase in the EMBI+ spread.

It is possible to evaluate the effectiveness of the Central Bank's policies on the exchange rate return by looking at the impulse response of the exchange rate return to one standard deviation shock to the change in interest rate, buying auctions and selling auctions. Normally, it would be expected that positive shocks to buying auctions would have a positive impact on the exchange rate, i.e., a depreciation. Figure 2 indicates that initial return response to one standard deviation shock to buying auction (21 million USD increase), however, is negative (appreciation) ( $0.1 \%$ decrease) and becomes positive

\footnotetext{
${ }^{5}$ The full estimation results in this section are not reported in order to save space. They are available from the authors upon request.
} 
(a) Response to EMBI+ Spread

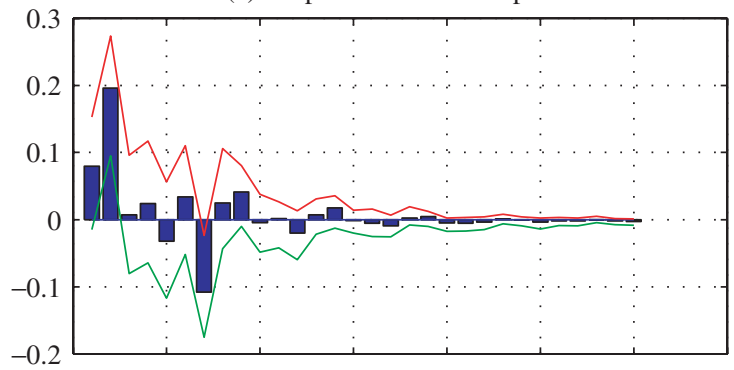

(c) Response to Exchange Rate Volatility

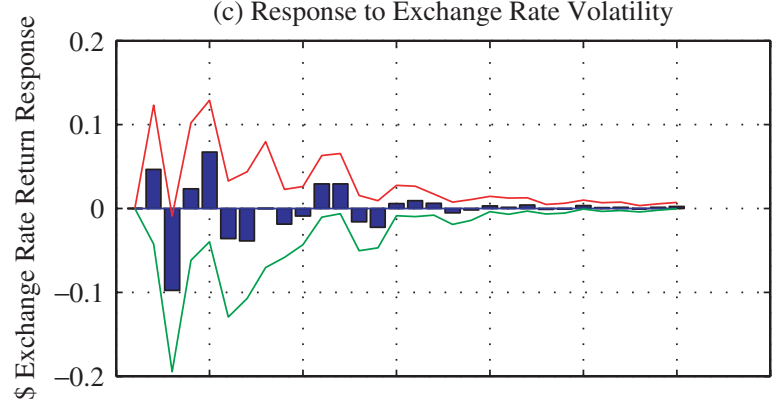

(e) Response to Auction (Buy)

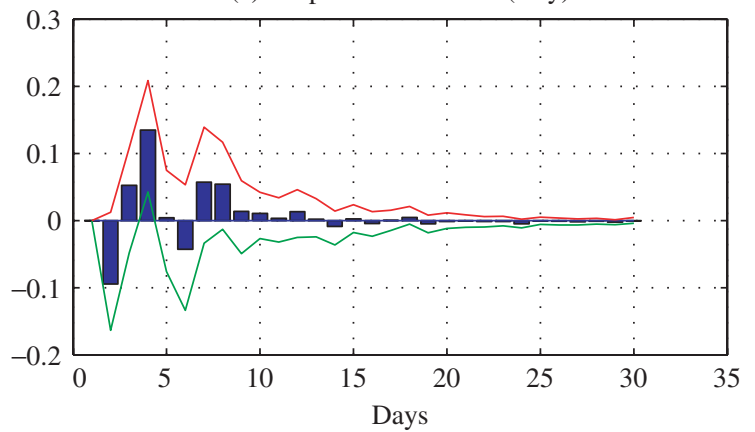

(b) Response to Exchange Rate Return

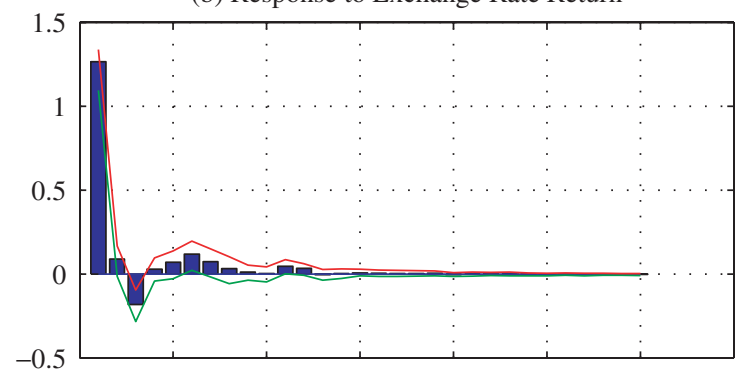

(d) Response to Interest Rate Change

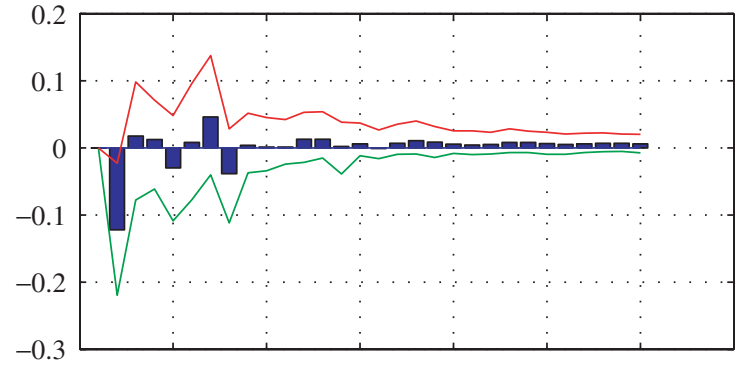

(f) Response to Auction (Sell)

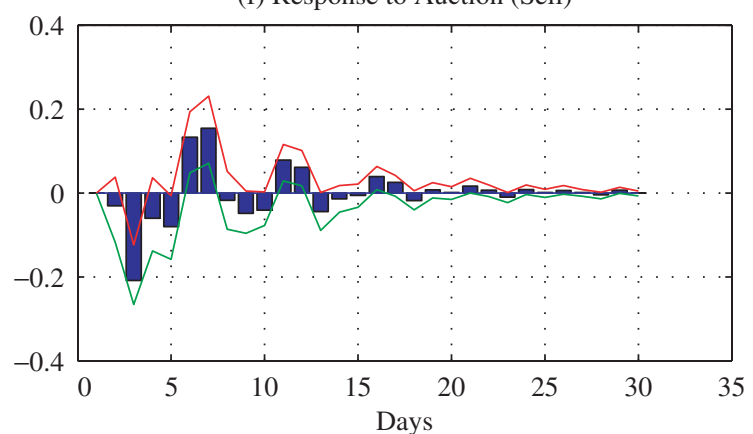

Fig. 2. TRL/USD daily exchange rate return (log difference) response to shocks to different variables in the system. (a) Response to a shock (11.05\% increase) in EMBI+ Spread. (b) Response to a shock $(1.36 \%$ increase) in TRL/USD daily exchange rate return. (c) Response to a shock $(1.06 \%$ increase) in TRL/USD daily volatility (absolute return). (d) Response to a shock $(0.60 \%$ increase) in change in overnight interest rates. (e) Response to a shock (21 Million USD increase) in Central Bank USD buying auction. (f) Response to a shock (30 Million USD increase) in Central Bank selling auction. 95\% bootstrap confidence intervals are plotted as straight lines. Sample period: 13 March 2001 - 30 October 2003 (667 business days)

only after two periods. Overall response, therefore, is close to zero. On the other hand, a shock to selling auctions (30 million USD increase) results in a negative response from the exchange rate return, as expected. But the response reverses itself and becomes positive after four periods $(0.03 \%, 0.2 \%$, $0.06 \%$ and $0.08 \%$ declines are followed by increases of $0.13 \%$ and $0.15 \%$ ). The overall response is, again, close to zero. The response of the exchange rate return to a positive shock in the overnight interest rate change (60 basis points increase) is negative after one day $(0.1 \%$ decrease), followed by subsequent positive and negative impacts which offset one another and eventually die out in eight days. In sum, the exchange rate responses to the Central Bank policy instruments show that the
Bank did not influence the exchange rate return during the float.

In several announcements, the policymakers made it clear that the exchange rate volatility would be a concern for the Central Bank. The response of exchange rate volatility to shocks to different variables in the system is plotted in Fig. 3. The response of exchange rate volatility to a positive shock to the EMBI+ spread (11 percentage points increase) is not significant first, and becomes significantly positive after five days $(0.06 \%$ and $0.09 \%$ increases $)$. That is, an unexpected increase in the EMBI+ spread increases the exchange rate volatility. Given the symmetric nature of the impulse responses, we may infer that an unexpected decrease in the spread is followed by a fall in volatility. The recent fall in this spread 
(a) Response to EMBI+ Spread

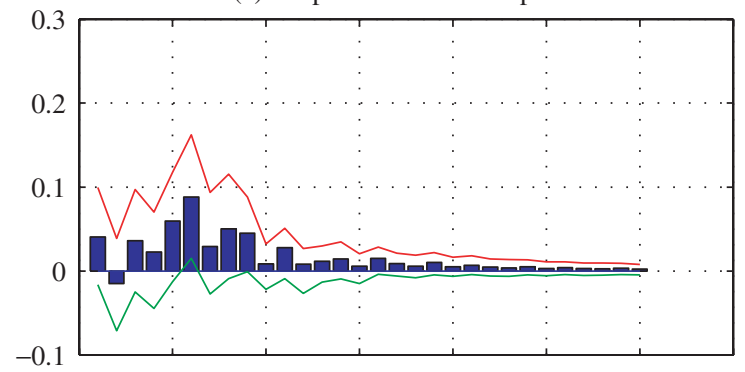

(c) Response to Exchange Rate Volatility

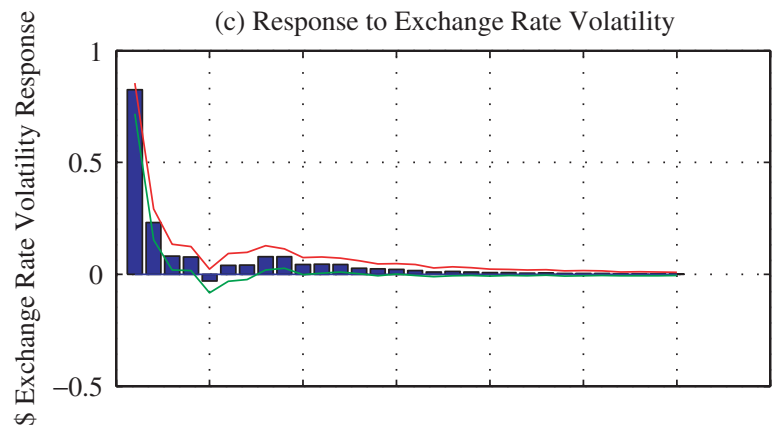

(e) Response to Auction (Buy)

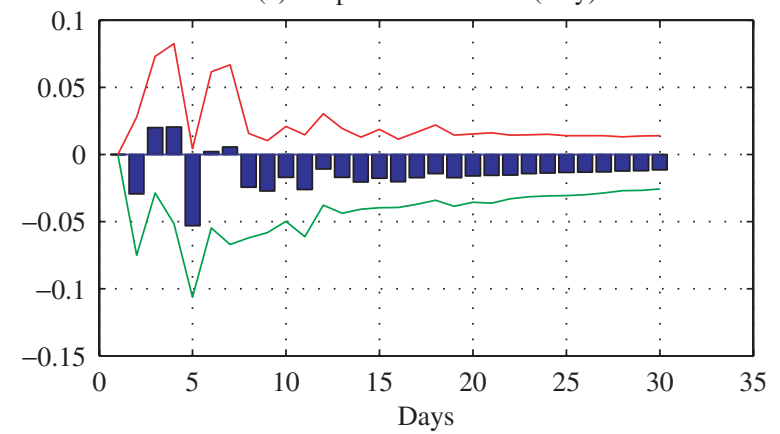

(b) Response to Exchange Rate Return

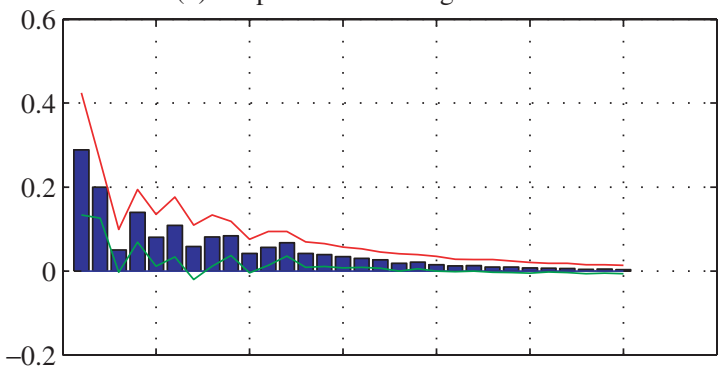

(d) Response to Interest Rate Change

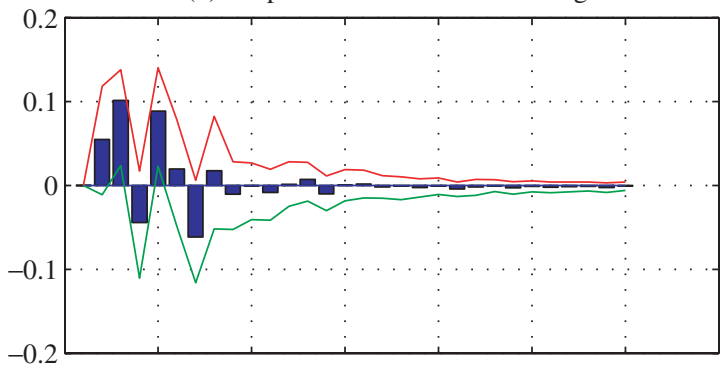

(f) Response to Auction (Sell)

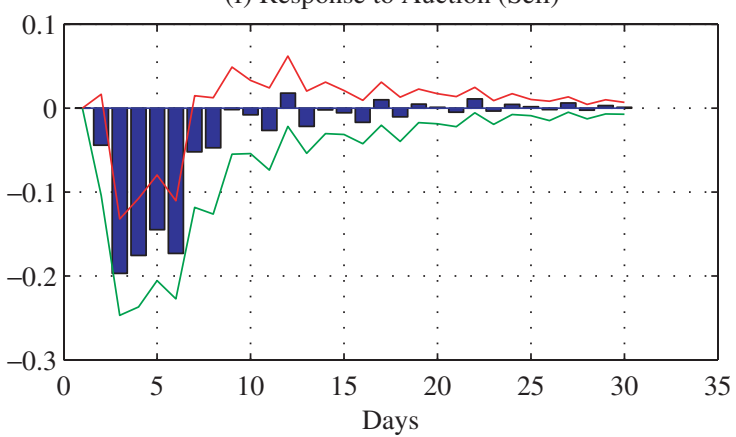

Fig. 3. TRL/USD daily exchange rate volatility response to shocks to different variables in the system. (a) Response to a shock (11.05\% increase) in EMBI+ Spread. (b) Response to a shock (1.36\% increase) in TRL/USD daily exchange rate return. (c) Response to a shock $(1.06 \%$ increase) in TRL/USD daily volatility (absolute return). (d) Response to a shock $(0.60 \%$ increase) in change in overnight interest rates. (e) Response to a shock (21 Million USD increase) in Central Bank USD buying auction. (f) Response to a shock (30 Million USD increase) in Central Bank selling auction. 95\% bootstrap confidence intervals are plotted as straight lines. Sample period: 13 March 2001 - 30 October 2003 (667 business days)

(see Fig. 1) is probably one of the positive factors in containing the exchange rate volatility in Turkey. Concerning the Central Bank policies, the response of volatility to shocks to buying and selling auctions and shocks to indicative interest rate may be evaluated. Among these, the volatility response to selling auction shocks (30 million USD increase) is the most noticeable. The response is statistically significant and negative for five days $(0.04 \%$ decrease after one day followed by subsequent declines ranging between $0.15 \%$ and $0.2 \%$ ) indicating that the selling auction was effective in containing the volatility. Similarly, interest rate cuts were effective in reducing the exchange rate volatility: an unexpected cut in the overnight interest rates of 60 basis points leads to a decline in the volatility of the exchange rate by $0.05 \%$ one day after and $0.1 \%$ two days after. A shock to buying auction, on the other hand, does not have any significant effect: the central bank was simply accumulating its foreign exchange reserves through buying auctions without affecting the exchange rate return or its volatility.

The findings in this part indicate that the Central Bank was effective in taming the exchange rate volatility without influencing the exchange rate return. In this process, a favourable external factor (the recent falling spread between emerging market bonds and US treasury bills) seems to be a crucial factor which signals that any adverse development in this front would make the Central Banks' job more difficult than before. 
Table 2. Exchange rate return series: summary statistics (daily, in \%). Subsamples: the first 160 days: 13 March $2001-25$ October 2001; the following 378 days: 26 October 2001 - 30 April 2003; and the last 129 days: 1 May 2003 - 30 October 2003

\begin{tabular}{lccrr}
\hline & Full & 1st & 161st & \multicolumn{1}{c}{$\begin{array}{l}\text { May 03 } \\
\text { Oct 03 }\end{array}$} \\
\hline Sample & May 03 days & -0.01 & -0.04 \\
Standard deviation & 0.07 & 0.34 & 0.92 & 0.70 \\
Excess Kurtosis & 1.36 & 2.30 & 1.63 & 0.10 \\
Skewness & 12.14 & 4.16 & 0.70 & 0.36 \\
Maximum & 1.27 & 0.69 & 3.51 & 1.79 \\
Minimum & 10.05 & 10.05 & -2.19 & -2.03 \\
Sample size (days) & -8.36 & -8.36 & 378 & 129 \\
\hline
\end{tabular}

\section{Volatility Dynamics of the Exchange Rate}

In the aftermath of the float, the volatility of the foreign exchange rate return was extremely large for the first few months. This high volatility period was followed by a relatively low volatility for about 18 months. After the first quarter of 2003 until the end of the sample period, the TRL/USD exchange rate return has experienced a period of relative tranquility. In this part, the volatility dynamics of the exchange rate during the full sample are analysed, as well as three subsamples, defined as the first 160 days (13 March 2001 - 25 October 2001), the following 378 days (26 October 2001 - 30 April 2003) and the last 129 days (1 May 2003 - 30 October 2003).

Table 2 gives the summary statistics for the daily exchange rate return series over the sample period, 13 March 2001 - 30 October 2003, and three subsamples. The mean and the standard deviation of the daily return series for the full sample are $0.07 \%$ (20\% annual compound) and $1.36 \%$ however, that the behaviour of the exchange rate return is different across subsamples. During the first 160 days of the float, the series has higher mean and volatility. In the second subsample, which runs through 26 October 2001 - 30 April 2003, exchange rate return shows lower volatility and has a lower mean than the initial period. The daily mean return is positive $(0.34 \%, 141.7 \%$ annual compound) in the initial period, and becomes negative in the subsequent periods: $-0.01 \%(-2.6 \%$ annual compound), and $-0.04 \%$ ( $-9.9 \%$ annual compound). The standard deviation of the return series has also declined from a high of $2.30 \%$ in the initial period to a low of $0.70 \%$ in the final period. For the first two subsamples, the return series display excess kurtosis and positive skewness. However, for the final period these values are not statistically significant to imply a deviation from normality.

The unit root tests on the foreign exchange rate series show no evidence of a unit root. Using the Box-Jenkins approach, the best fitting model for the TRL/USD exchange rate return series is found to be an $\operatorname{ARMA}(2,1){ }^{6}$ The squared residuals of the $\operatorname{ARMA}(2,1)$ model displays serial correlation suggestive of an ARCH-type process. After some preliminary investigation, it was decided to estimate the following $\operatorname{ARMA}(2,1)-\operatorname{GARCH}(1,1)$ for the full sample and three subsamples ${ }^{7}$ :

$$
\begin{aligned}
r_{t} & =a_{0}+a_{1} r_{t-1}+a_{2} r_{t-2}+b_{1} \epsilon_{t-1}+\epsilon_{t}, \\
\sigma_{t}^{2} & =c+\alpha_{1} \epsilon_{t-1}^{2}+\beta_{1} \sigma_{t-1}^{2}
\end{aligned}
$$

where $\epsilon_{t}=\eta_{t} \sigma_{t}$ and $\eta_{t}$ is a white noise process with $\sigma_{\eta}^{2}=1$. Notice that the parameter $\alpha_{1}$ in Equation 1 shows the extent to which a volatility shock today feeds through into next period's volatility while $\left(\alpha_{1}+\beta_{1}\right)$ measures the rate at which this effect dies out over time (Campbell et al., 1997, p. 483). In other words, $\alpha_{1}$ indicates the level of persistency in 'volatility of volatility.' Therefore, a decrease in this parameter may be interpreted as a strong indication of containing the volatility. Regarding $\left(\alpha_{1}+\beta_{1}\right)$, a useful measure is known as 'half-life' $(h l)$ which gives the necessary time after a shock to halve its impact:

$$
h l=\frac{\log (0.5)}{\log \left(\alpha_{1}+\beta_{1}\right)}
$$

For example, given $\left(\alpha_{1}+\beta_{1}\right)=0.90$, it would take approximately seven days after a shock to halve its impact while $\left(\alpha_{1}+\beta_{1}\right)=0.80$ implies that half life is only three days, provided that there are no

\footnotetext{
${ }^{6}$ The results of the unit root tests and $\operatorname{ARMA}(\mathrm{p}, \mathrm{q})$ modeling are not fully reported. These are available from the authors upon request.

${ }^{7}$ A GARCH-M (GARCH in mean) model was also estimated for all samples to see whether the exchange rate return depends on its volatility or not. The risk premium parameter in the return equation was not significant.
} 
other shocks. Also notice that the unconditional mean of $\epsilon_{t}^{2}$ is given by

$$
E\left(\epsilon_{t}^{2}\right)=\frac{c}{1-\left(\alpha_{1}+\beta_{1}\right)}
$$

provided that $\left(\alpha_{1}+\beta_{1}\right)<1$.

Estimation results are presented in Table 3 for the full sample and three subsamples. In order to check the robustness of the results, the model was estimated with normally distributed, Student's $t$ distributed and with generalized error distribution
(GED) residuals. According to the parameters of the ARMA model, the unconditional mean of the daily exchange rate return is estimated as 0.32 for the first period, -0.005 for the second period, and -0.027 for the last period. Notice that these values are very close to the sample statistics (see Table 2).

Likelihood values (not reported) and standard errors of the parameters indicate that GED model performs best for the first period and Student's $t$ and the GED models perform better than the

Table 3. The estimation results of ARMA(2,1)-GARCH(1,1) model with the Normal $(N)$, Student's $t(t)$ and the GED residuals. The model is estimated for the whole sample as well as three subsamples: the first 160 days (13 March 2001 - 25 October 2001), the following 378 days (26 October 2001 - 30 April 2003) and the last 129 days (1 May 2003 - 30 October 2003). Standard errors are in parentheses. See the text for an explanation of $h l$ (half-life) and the unconditional means of the squared shocks, $E\left(\epsilon_{t}^{2}\right)$, and the daily exchange rate return, $E\left(r_{t}\right)$

\begin{tabular}{|c|c|c|c|c|}
\hline & Full sample & 1st 160 days & 161st May 2003 & May 2003-Oct 2003 \\
\hline \multicolumn{5}{|c|}{$\operatorname{ARMA}(2,1)$} \\
\hline Constant & $\begin{array}{c}0.0651 \\
(0.0550)\end{array}$ & $\begin{array}{c}0.3096 \\
(0.1755)\end{array}$ & $\begin{array}{c}-0.0066 \\
(0.0614)\end{array}$ & $\begin{array}{c}-0.0401 \\
(0.0862)\end{array}$ \\
\hline$\hat{a}_{1}$ & $\begin{array}{c}0.0881 \\
(0.1608)\end{array}$ & $\begin{array}{c}0.1883 \\
(0.1614)\end{array}$ & $\begin{array}{c}-0.2083 \\
(0.2376)\end{array}$ & $\begin{array}{c}-0.3710 \\
(0.2130)\end{array}$ \\
\hline$\hat{a}_{2}$ & $\begin{array}{c}-0.1523 \\
(0.0689)\end{array}$ & $\begin{array}{c}-0.2112 \\
(0.0966)\end{array}$ & $\begin{array}{c}-0.0677 \\
(0.0625)\end{array}$ & $\begin{array}{c}-0.0847 \\
(0.0860)\end{array}$ \\
\hline$\hat{b}_{1}$ & $\begin{array}{c}0.0076 \\
(0.2257)\end{array}$ & $\begin{array}{c}-0.1268 \\
(0.2408)\end{array}$ & $\begin{array}{c}0.3358 \\
(0.2350)\end{array}$ & $\begin{array}{c}0.4331 \\
(0.2060)\end{array}$ \\
\hline$E\left(r_{t}\right)(\%)$ & 0.061 & 0.32 & -0.005 & -0.027 \\
\hline $\begin{array}{l}\text { GARCH(1 } \\
\text { Constant }\end{array}$ & $\begin{array}{c}0.0363 \\
(0.0168)\end{array}$ & $\begin{array}{c}3.6303 \\
(3.7655)\end{array}$ & $\begin{array}{c}0.0875 \\
(0.0369)\end{array}$ & $\begin{array}{c}0.0595 \\
(0.0300)\end{array}$ \\
\hline$\hat{\alpha}_{1}$ & $\begin{array}{c}0.1804 \\
(0.0430)\end{array}$ & $\begin{array}{c}1.0000 \\
(3.8359)\end{array}$ & $\begin{array}{c}0.3494 \\
(0.1346)\end{array}$ & $\begin{array}{c}0.1184 \\
(0.0659)\end{array}$ \\
\hline$\hat{\beta}_{1}$ & $\begin{array}{c}0.8135 \\
(0.0261)\end{array}$ & $\begin{array}{c}0.0000 \\
(0.2024)\end{array}$ & $\begin{array}{c}0.5936 \\
(0.0830)\end{array}$ & $\begin{array}{c}0.7593 \\
(0.0237)\end{array}$ \\
\hline$h l$ (days) & 115 & n.a. & 11.8 & 5.3 \\
\hline$E\left(\epsilon_{t}^{2}\right)(\%)$ & 5.9 & n.a. & 1.53 & 0.49 \\
\hline $\begin{array}{l}\text { GARCH(1 } \\
\text { Constant }\end{array}$ & $\begin{array}{c}0.0860 \\
(0.0342)\end{array}$ & $\begin{array}{c}2.4815 \\
(6.8262)\end{array}$ & $\begin{array}{c}0.0749 \\
(0.0294)\end{array}$ & $\begin{array}{c}0.0568 \\
(0.0319)\end{array}$ \\
\hline$\hat{\alpha}_{1}$ & $\begin{array}{c}0.2784 \\
(0.0802)\end{array}$ & $\begin{array}{c}0.7139 \\
(1.9623)\end{array}$ & $\begin{array}{c}0.2724 \\
(0.0898)\end{array}$ & $\begin{array}{c}0.1216 \\
(0.0680)\end{array}$ \\
\hline$\hat{\beta}_{1}$ & $\begin{array}{c}0.6949 \\
(0.0572)\end{array}$ & $\begin{array}{c}0.0552 \\
(0.1363)\end{array}$ & $\begin{array}{c}0.6646 \\
(0.0550)\end{array}$ & $\begin{array}{c}0.7638 \\
(0.0236)\end{array}$ \\
\hline$d f$ & 5.02 & 3.1 & 8 & 30 \\
\hline$h l$ (days) & 25.6 & 2.6 & 10.6 & 5.7 \\
\hline$E\left(\epsilon_{t}^{2}\right)(\%)$ & 3.22 & 10.74 & 1.18 & 0.49 \\
\hline \multicolumn{5}{|c|}{ GARCH(1,1) (GED) } \\
\hline Constant & $\begin{array}{c}0.0567 \\
(0.0214)\end{array}$ & $\begin{array}{c}2.0713 \\
(0.6200)\end{array}$ & $\begin{array}{c}0.0817 \\
(0.0336)\end{array}$ & $\begin{array}{c}0.0577 \\
(0.0308)\end{array}$ \\
\hline$\hat{\alpha}_{1}$ & $\begin{array}{c}0.2159 \\
(0.0572)\end{array}$ & $\begin{array}{c}0.5472 \\
(0.2596)\end{array}$ & $\begin{array}{c}0.2902 \\
(0.1020)\end{array}$ & $\begin{array}{c}0.1211 \\
(0.0673)\end{array}$ \\
\hline$\hat{\beta}_{1}$ & $\begin{array}{c}0.7640 \\
(0.0397)\end{array}$ & $\begin{array}{c}0.0339 \\
(0.0736)\end{array}$ & $\begin{array}{c}0.6422 \\
(0.0650)\end{array}$ & $\begin{array}{c}0.7622 \\
(0.0230)\end{array}$ \\
\hline$v$ & 1.21 & 1.1 & 1.39 & 1.81 \\
\hline$h l$ (days) & 34 & 1.3 & 9.9 & 5.8 \\
\hline$E\left(\epsilon_{t}^{2}\right)(\%)$ & 2.82 & 4.94 & 1.21 & 0.49 \\
\hline
\end{tabular}


Normal for the second period. For the third subperiod, there is not much difference among all three models. The estimated degrees of freedom of Student's $t$ distribution $(d f)$ for all three subperiods also indicates that the Normal distribution assumption is inadequate, especially for the first two periods. The estimated $d f$ is 3.1 and 8 for the first two subsamples while it is 30 for the last period. Similarly, the parameter $v$ which governs the thickness of the tails in the GED model is estimated as 1.1 and 1.39 for the first and the second subperiod, respectively. For the last period, it is 1.81 . Notice that $v=2$ for the Normal distribution. If $v<2$ the GED density has thicker tails than the Normal, whereas for $v>2$ it has thinner tails. Based on these estimated parameters, it is safe to conclude that the exchange rate return has a Normal distribution after May 2003.

According to estimated parameters, there is a significant fall in the volatility of volatility from the beginning towards the end of the floating period. Estimated $\alpha_{1}$ in Equation 1 is around 0.71 (Student's $t$ ) and 0.55 (GED) during the first period which shows that volatility shocks were persistent at the beginning of the float. The same parameter is 0.12 (all three models) for the last period, indicating that volatility shock feeds into future volatility significantly less than before. This finding shows that the Central Bank policies, as well as favorable external factors, caused a significant reduction in the persistence of volatility. In other words, the spillover effect of the shocks to the volatility has been contained successfully.

Estimated half-life figures in Table 3 also show that it takes a short period of time after a shock to halve its impact in recent months. During the second period, estimated half-life is around ten days (GED) and 11 days (Student's $t$ ). The same figure is around five days (Normal) and six days (Student's $t$ and GED) during the last period. According to estimated parameters, there is also a significant fall in the unconditional mean of the daily squared shocks, $E\left(\epsilon_{t}^{2}\right)$, during the sample period. It was around 4.9 (GED) and 10.7 (Student's $t$ ) percent at the beginning of the float while it is less than $0.5 \%$ in the third period according to all models.

Figure 4 plots estimated daily conditional volatility series for the full sample and three subsamples. (a) Full Sample

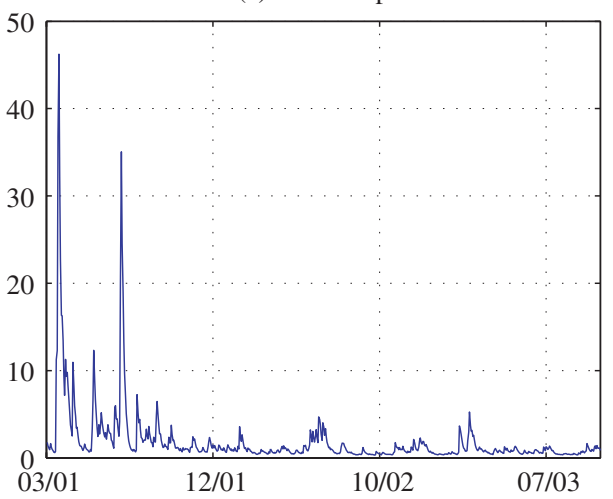

(c) $10 / 25 / 01-05 / 01 / 03$

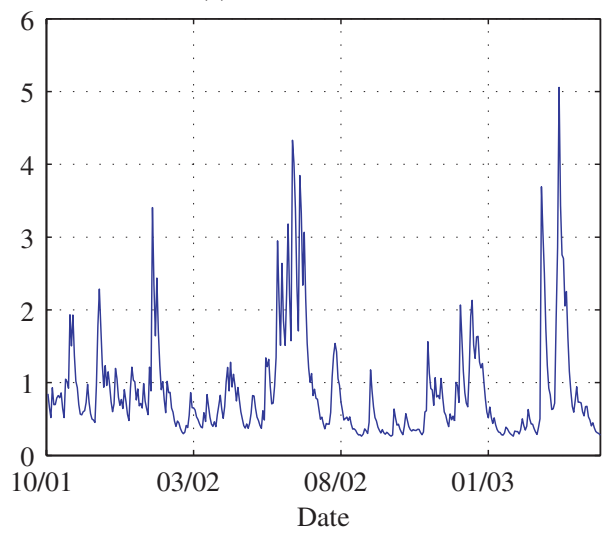

(b) $03 / 13 / 01-10 / 25 / 01$

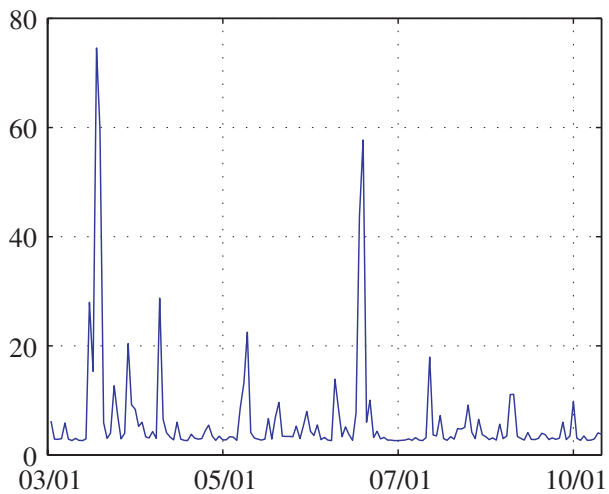

(d) Post 05/01/03

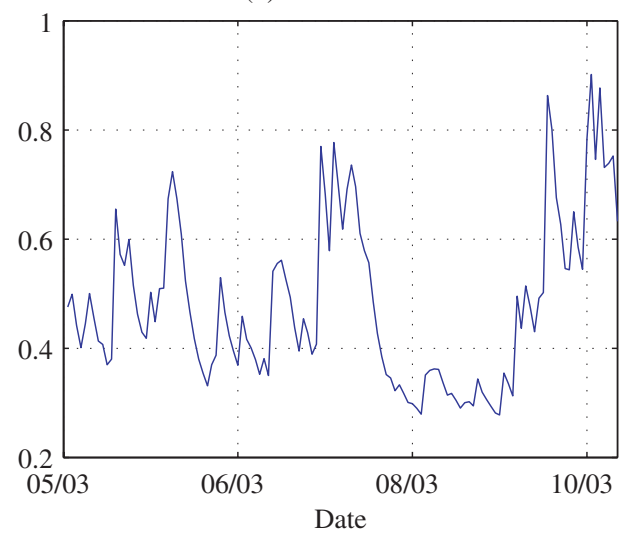

Fig. 4. Estimated conditional volatility (Student's $t$ distribution with different degrees of freedom). The model is estimated for (a) the whole sample, (b) the first 160 days (13 March 2001 - 25 October 2001), (c) the following 378 days (26 October 2001 - 30 April 2003) and (d) the last 129 days (1 May 2003 - 30 October 2003). See Table 3 for details 
There is a significant fall in conditional volatility series throughout the sample period. At the beginning of the float, the conditional volatility fluctuates around $10 \%$ with occasional large jumps as high as $60 \%$. During the last period, the same figure is fluctuating around $0.5 \%$ and never reaches over $1 \%$.

\section{Conclusion}

This paper analyses the recent floating exchange rate regime experience of Turkey in light of the Central Bank policies. The findings indicate that the Central Bank policies, accompanied with favourable external factors, were effective in taming the volatility of the exchange rate in a relatively short period of time. Estimated model parameters show that there is a significant fall in both the unconditional mean of the daily squared shocks to exchange rate return and conditional volatility throughout the floating exchange rate period. Furthermore, the distribution of exchange rate return seems to be the Normal in recent months. In this process, a favourable external factor (the recent falling spread between emerging market bonds and US treasury bills) seems to be a crucial factor which signals that any adverse development in this front would make the Central Banks' job more difficult than before. It remains to be investigated whether the spread between emerging market bonds and US treasury bills is a significant variable in explaining the exchange rate dynamics in other emerging market economies with a floating exchange rate regime. This is left for future research.

\section{Acknowledgements}

Faruk Selçuk gratefully acknowledges financial support from the Research Development Grant Program of Bilkent University.

\section{References}

Allen, M., Rosenberg, C., Keller, C., Setser, B. and Roubini, N. (2002) A balance sheet approach to financial crisis, IMF Working Paper No. WP $/ 02 / 210$.

Calvo, G. A. and Reinhart, C. M. (2001) Fixing for your life, in Brookings Trade Forum 2000. Policy Challenges for the Next Millennium (Eds) S. Collins and D. Rodrik, Brookings Institution, Washington DC.

Calvo, G. A. and Reinhart, C. M. (2002) Fear of floating, The Quarterly Journal of Economics, 117, 379-408.

Calvo, G. A., Izquierdo, A. and Talvi, E. (2003) Sudden stops, the real exchange rate, and fiscal sustainability: Argentina's lessons, NBER Working Paper No. WP9828.
Campbell, J. Y., Lo, A. W. and MacKinlay, A. C. (1997) The Econometrics of Financial Markets, Princeton University Press, Princeton, NJ.

Cavallo, M., Kisselev, K., Perri, F. and Roubini, N. (2002) Exchange rate overshooting and the costs of floating, Mimeo, New York University.

Celasun, O., Gelos, R. G. and Prati, A. (2003) Would cold turkey work in Turkey? IMF Working Paper No. WP/03/49.

Cespedes, L. F., Chang, R. and Velasco, A. (2000) Balance sheets and exchange rate policy. NBER Working Paper No. WP7840.

Domaç, I. and Bahmani-Oskooee, M. (2002) On the link between dollarization and inflation: evidence from Turkey, Discussion Paper, The Central Bank of the Republic of Turkey.

Dornbusch, R. (2001) A primer on emerging market crises, Manuscript, Department of Economics, MIT.

Eichengreen, B. (2001) Crisis prevention and management: any new lessons from Argentina and Turkey? Background paper written for the World Banks Global Development Finance 2002, University of California, Berkeley, CA.

Ertuğrul, A. and Selçuk, F. (2002) Turkish economy: 1980-2001, in Inflation and Disinflation in Turkey (Eds) A. Kibritçioğlu, L. Rittenberg and F. Selçuk, Ashgate Publishing Company, Aldershot.

Fischer, S. (2001) Exchange rate regimes: Is the bipolar view correct? Journal of Economic Perspectives, 15, 3-24.

Gençay, R. and Selçuk, F. (2005) Overnight borrowing, interest rates and extreme value theory, European Economic Review (forthcoming).

Kenen, P. B. (1969) The theory of optimum currency areas: an eclectic view, in Monetary Problems of the International Economy (Eds) R. A. Mundell and A. K. Swoboda. University of Chicago Press, Chicago.

Kibritçioğlu, A., Rittenberg, L. and Selçuk, F. (2002) Inflation and Disinflation in Turkey (Eds) A. Kibritçioğlu, L. Rittenberg and F. Selçuk, Ashgate Publishing Company, Aldershot.

Lim, C. H. and Papi, L. (1997) An econometric analysis of determinants of inflation in Turkey, IMF Working Paper No. WP/97/170.

McKinnon, R. I. (1963) Optimum currency areas, American Economic Review, 53, 717-25.

Metin, K. (1995) An integrated analysis of Turkish inflation, Oxford Bulletin of Economics and Statistics, 57, 513-31.

Metin-Özcan, K., Voyvoda, E. and Yeldan, A. E. (2001) Dynamics of macroeconomic adjustment in a globalized developing economy: growth, accumulation and distribution, Turkey 1969-1999, Revue Canadienne d'Etudes du Developpement, 22, 219-53.

Mundell, R. A. (1961) A theory of optimum currency areas, American Economic Review, 51, 657-65.

Mussa, M., Masson, P., Swoboda, A., Jadresic, E., Mauro, P. and Berg, A. (2000) Exchange rate regimes in an increasingly integrated world economy, IMF Occasional Paper No. 193.

Obstfeld, M. and Rogo, K. (1995) The mirage of fixed exchange rates, Journal of Economic Perspectives, 9, 73-96.

Öniş, Z. and Rubin, B. (2003) Turkish economy in crisis, in (Eds) Ziya Öniş and B. Rubin, Frank Cass \& Co., London. 
Reinhart, C. M. (2000) The mirage of floating exchange rates, American Economic Review Papers and Proceedings, 90, 65-70.

Selçuk, F. and Ardıc, O. P. (2005) Learning to live with the float: Turkey's experience 2001-2003. In Contemporary Issues in International Finance (Ed.) F. Columbus, Nova Science Publishers Inc., NY (forthcoming).

Sims, C. A. (1980) Macroeconomics and reality. Econometrica, 48, 1-48.
Tavlas, G. (2003) The economics of exchange rate regimes: a review essay, The World Economy, 26, 1215-46.

Taylor, M. P. and Sarno, L. (2001) Official intervention in the foreign exchange market: Is it effective and, if so, how does it work? Journal of Economic Literature, 39, 839-68.

Taylor, M. P. and Sarno, L. (2002) The Economics of Exchange Rates, Cambridge University Press, Cambridge. 